\title{
Mediatisasi dan Budaya: Pengalaman Peminat Gen Z Gelombang Korea Malaysia Mengharungi Pandemik Global Covid-19
}

\author{
NURUL AKQMIE BINTI BADRUL HISHAM \\ ABDUL LATIFF AHMAD \\ CHANG PENG KEE \\ Universiti Kebangsaan Malaysia
}

\begin{abstract}
ABSTRAK
Gelombang Korea merupakan suatu fenomena global yang menjadikan media sosial sebagai platform utama untuk mengetengahkan produk budaya. Memiliki peminat di setiap pelosok dunia, fenomena ini bersesuaian untuk dijadikan sebagai subjek kajian dalam meneliti kesan proses perkembangan teknologi media terhadap perubahan kehidupan masyarakat. Artikel ini bertujuan untuk meneroka proses mediatisasi dalam kalangan sesuatu masyarakat. Hal ini memperlihatkan suatu usaha untuk meneliti bagaimana teknologi media, memainkan peranan dalam perubahan budaya harian masyarakat. Fokus kajian tertumpu pada hubungan antara peminat generasi $Z$ dengan fenomena gelombang Korea. Kajian ini menggunakan pendekatan kualitatif iaitu teknik pengumpulan data netnografi. Sampel dipilih berdasarkan kriteria yang telah ditetapkan dan kemudiannya dianalisis menggunakan perisian Nvivo12, untuk memperoleh hasil dapatan kajian. Pengkaji memperhaluskan lagi kajian, dengan hanya memfokuskan kepada garis masa ketika tempoh perintah kawalan pergerakan sahaja. Pengkaji berusaha untuk mendalami bagaimana kemandirian industri hiburan Korea Selatan dalam menghubungkan produk budaya mereka dengan peminat antarabangsa ketika penularan pandemik Covid-19.Kajian ini mendapati walaupun dunia dilanda pandemik global, penerimaan dan penggunaan produk budaya Korea terutamanya acara seperti konsert, pertemuan peminat dan sebagainya lagi, masih lagi berterusan dalam kalangan peminat. Disebabkan oleh kesedaran terhadap digitalisasi yang tinggi dalam kalangan generasi $Z$, pengalaman peminat seperti menghadiri konsert dan perkongsian maklumat masih boleh dilakukan menggunakan aplikasi dalam talian dan peranti komunikasi media seperti telefon bimbit, komputer dan juga tablet. Teknologi komunikasi media tanpa disedari telah mengubah cara manusia berkomunikasi dan juga budaya harian manusia.
\end{abstract}

Kata kunci: Mediatisasi, gelombang Korea, netnografi, gen Z, Covid-19.

\section{Mediatization and Culture: Korean Wave and Malaysia's Gen Z Fan in the Global Pandemic Covid-19}

\begin{abstract}
Korean Wave is a global phenomenon that has made social media a major platform for promoting cultural products. Having fans from all over the world demonstrates its suitability to be a subject of study in the process of how the development of media technology has transformed people's lives. This article aims to explore the process of mediatization in society. This study seeks to explore how media technology plays a role in changing the culture of every day. Looking at the Korean wave, the researcher sought to understand the relationship between fans among gen $Z$ and the phenomenon. This study is a qualitative research, using nethnography as a data collection technique. Samples were selected based on predefined criteria and then used Nvivo12 software to analyse the findings. The researcher further refined this study by focusing on the duration of movement control order only. This
\end{abstract}


study seeks to understand how the entertainment industry survived and the relationship between the Korean wave phenomenon and fans in the face of a pandemic. The study found that despite the global pandemic, with a high level of digitalization among gen $Z$, the consumption of Korean cultural products among fans is still ongoing. Fan experience such as attending concerts and sharing information can still be done using the applications via media communication devices such as mobile phones, computers and tablets. The development of media communication technologies, change the way people communicate and the culture of every day.

Keywords: Mediatization, Korean wave, netnography, gen Z, Covid-19.

\section{PENGENALAN}

Bermula pada abad ke-17, munculnya surat khabar pertama di dunia dan media massa sentiasa berkembang dan berpelbagai sehingga ke hari ni. Justeru itu, perkembangan media massa telah meninggalkan artifak yang memberi makna tertentu kepada masyarakat. Media memainkan peranan tertentu dalam kehidupan manusia, sama ada untuk berkomunikasi secara peribadi atau untuk menyebarkan mesej kepada orang ramai. Deuze (2012) memberi perumpamaan bahawa, hubungan media dengan manusia adalah seperti air untuk ikan. Perumpamaan yang diberikan oleh Deuze ini memperlihatkan setiap aspek kehidupan masyarakat bergantung pada media. Oleh yang demikian, media bukan sahaja teknologi bahkan merupakan sebahagian daripada kandungan yang berkongsi dunia yang sama seperti manusia.

Couldry dan Hepp (2017) pula menjelaskan tentang perkembangan teknologi media dan komunikasi telah membawa kepada perubahan dalam cara masyarakat berkomunikasi. Sebagai contoh, melihat kepada teknologi komunikatif dan media, iaitu sebuah telefon bimbit telah menjadi sebahagian dalam kehidupan manusia. Contohnya, telefon bimbit yang memainkan beberapa peranan seperti, untuk berhubung, menggantikan jam loceng, kalendar, radio, surat khabar malah televisyen untuk sesetengah pihak. Hal ini diulas oleh para sarjana komunikasi media sebagai satu meta-proses yang disebut sebagai mediatisasi.

Mediatisasi merupakan suatu aspek kajian yang luas dan mengulas tentang perubahan manusia sejajar dengan perkembangan teknologi komunikasi dan media. Sarjana mediatisasi menekankan kajian mengenai mediatisasi ini tidak boleh dilakukan secara menyeluruh dan hanya memfokuskan kepada kumpulan-kumpulan kecil dalam masyarakat (Krotz, 2007; Hepp, 2009; Hepp, Hjarvard \& Lundy, 2010). Tambahan lagi, penyelidik perlu memfokuskan untuk menjelaskan perkara yang berlaku didorong oleh media sebagai satu alat pengantaraan untuk berkomunikasi.

Masyarakat kini berada pada suatu keadaan di mana, Internet digunakan untuk menggantikan aktiviti harian utama kepada aktiviti yang boleh dilakukan di dalam talian. Aktiviti dalam talian dilakukan sama ada melalui laman sesawang atau menggunakan laman media sosial, lebih memudahkan individu dan menjimatkan masa. Dengan kata lain, telefon bimbit, komputer riba dan peranti pintar telah menjadi sebahagian daripada kehidupan kita. Perkara ini membawa kepada peningkatan kepada penggunaan media dan sekali gus mewujudkan proses mediatisasi dalam kalangan manusia.

Kajian ini bukan hanya memfokuskan kepada salah satu cabang mediatisasi iaitu mediatisasi dan budaya, tetapi juga mendalami proses mediatisasi ini dengan perspektif kualitatif. Hepp (2009) menjelaskan untuk menggunakan teori mediatisasi dan budaya sebagai suatu kerangka analisis kualitatif, pengkaji perlu meletakkan fokus berganda kepada cara penyebaran sesuatu media itu berkaitan dengan perubahan budaya yang khusus. Dari 
situ, akan membawa kepada pemahaman terhadap peningkatan makna dalam media dan komunikasi pengantaraan. Dengan kata lain, kajian mediatisasi dan budaya tidak hanya memfokuskan kepada kesan tetapi juga mendalami proses transformasi yang berlaku (Krotz, 2007 \& Hepp, 2009). Oleh itu, tujuan utama makalah ini adalah untuk meneroka perkaitan perubahan dalam teknologi media yang menstrukturkan cara manusia berkomunikasi.

\section{GENERASI Z DAN FENOMENA GELOMBANG KOREA}

Perbincangan tentang isu kebergantungan terhadap media dan teknologi sering dikaitkan dengan generasi muda, terutamanya generasi Z. Menurut Gaidhani et al. (2019), generasi Z dilahirkan dan dibesarkan dengan teknologi terkini, bersifat digital sentrik dan teknologi adalah identiti mereka. Pada tahun 2020, generasi Z yang dilahirkan selepas 1995, akan mewakili lebih daripada 30\% tenaga kerja. Dolot (2018) pula menjelaskan walaupun masih muda, generasi $Z$ ini aktif secara profesional dan ini boleh mempengaruhi keputusan gaya hidup dan kehidupan mereka. Perkara ini menjadikan generasi $Z$ menjadi satu isu yang menarik untuk penyelidikan masa depan. Memahami dan mendalami cara generasi $Z$ berkomunikasi pada masa ini adalah penting, terutamanya untuk melihat bagaimana perubahan dalam teknologi media mengubah cara manusia berkomunikasi.

Melihat kepada saranan sarjana-sarjana yang mengembangkan kajian mediatisasi, pengkaji memperkecilkan skop kajian untuk memfokuskan kepada isu dalam kalangan peminat gelombang Korea sahaja. Menurut Korean Culture dan Information Service (2011), peminat gelombang Korea majoriti berasal dari golongan remaja terutamanya belia yang berumur 20 -an dan $90 \%$ adalah golongan perempuan. Pemilihan peminat gelombang Korea sebagai subjek kajian menepati ciri-ciri generasi $Z$ yang telah ditetapkan oleh sarjana terdahulu. Fenomena gelombang Korea pula merupakan suatu fenomena global yang pada masa ini, menjadikan media sosial sebagai pentas utama untuk mengetengahkan produk mereka.

Pengkaji memperhaluskan lagi kajian ini dengan hanya memfokuskan kepada garis masa ketika dunia dilanda pandemik Covid-19. Pengkaji berusaha untuk mendalami bagaimana kemandirian industri hiburan Korea Selatan dalam menghubungkan produk budaya mereka dengan peminat antarabangsa ketika penularan pandemik Covid-19. Pengkaji berharap kajian ini boleh menjawab kepada persoalan adakah fenomena gelombang Korea akan terancam apabila dilanda penularan pandemik Covid-19?. Ini disebabkan oleh kebanyakan acara hiburan termasuk acara gelombang Korea telah dibatalkan secara tiba-tiba di seluruh dunia. Meskipun tiket-tiket acara telah dijual dan lokasi acara juga telah ditetapkan, pihak penganjur terpaksa membayar balik ganti rugi kepada peminat. Namun demikian, ramai peminat masih tidak berpuas hati dan memilih media sosial untuk meluahkan kekecewaan mereka.

Pemilihan skop kajian dari segi masa pula, ini disebabkan oleh tempoh yang berlaku secara serentak di seluruh dunia dan pengkaji meneliti bagaimana industri hiburan Korea Selatan menangani krisis yang berlaku. Walaupun kes pertama Covid-19 di Malaysia dikesan pada 24 Januari 2020, (“Coronavirus disease (COVID-19) in Malaysia," 29 Jun 2020) kerajaan Malaysia hanya melakukan perintah kawalan pergerakan bermula pada 18 Mac 2020 sebagai usaha mengekang penularan Covid-19. Walau bagaimanapun, acara gelombang Korea telah dibatalkan oleh syarikat pengurusan dan pihak penganjur tempatan seawal bulan Februari 2020. 


\section{MEDIATISASI DALAM KEHIDUPAN HARIAN GENERASI Z}

Menurut Hutchings (2020), mediatisasi merujuk cara media menembusi aspek-aspek seperti politik, peperangan dan juga kehidupan harian masyarakat kontemporari. Wojtkowski (2017) pula menerangkan bahawa, teori mediatisasi memberi satu sudut pandangan baharu dalam memahami kedinamikan kajian media dan komunikasi pada masa ini. Tambahan itu, menurut Turner (2016), teori mediatisasi dan budaya meletakkan titik fokus kepada perubahan yang dibawa oleh teknologi media terhadap sosiobudaya masyarakat. Rentetan itu, teori mediatisasi dan budaya turut menghujahkan tentang bagaimana masyarakat kini telah memasuki sesuatu "kawasan" yang berbeza daripada masyarakat sebelum ini. "Kawasan" merujuk kepada situasi media massa dan hubungan sosial itu telah berkembang dan berbeza dengan keadaan pada masa lalu. Tambahan lagi, Turner (2016) juga menjelaskan keadaan media massa yang juga berfungsi dalam kadar yang cepat dan mudah runtuh, walaupun khalayak belum mampu untuk mengasimilasikan dengan perubahan yang berlaku. Hjarvard (2008) menjelaskan bahawa, budaya yang dibincangkan dalam konteks mediatisasi adalah budaya remeh (trivial), yang dikaitkan dengan cara hidup masyarakat tempatan. Hjarvard juga menerangkan keadaan media hari ini telah berada pada kedudukan dominan sebagai institusi, yang menyediakan produk budaya dan juga kepercayaan kepada khalayak sesuatu masyarakat itu.

Mediatisasi boleh difahami sebagai perubahan yang berkaitan dengan perkembangan komunikasi media dan pada masa yang sama, membawa kepada perubahan yang berlaku kepada masyarakat. Menurut Schulz (2004), mediatisasi merujuk kepada proses perubahan sosial apabila media memainkan peranan utama dan proses ini boleh ditakrifkan sebagai lanjutan (extension), penggantian (substitute), penggabungan (amalgamation) dan penyesuaian (accommodation) kepada aktiviti-aktiviti manusia.

Selain itu, mediatisasi melihat media sebagai sebahagian daripada masyarakat dan mempunyai pengaruh atau kesan tertentu terhadap budaya dan individu (Hepp, Hjarvard, \& Lundby, 2010). Oleh itu, mereka mengatakan perlunya rangka kerja konseptual untuk mempertimbangkan pengaruh media, yang mencerminkan keadaan sosial baharu masyarakat yang hidup dalam keadaan tepu media. Corner (2018) pula menjelaskan bahawa, perlunya pemerhatian yang lebih lanjut dalam kajian mediatisasi untuk memperlihatkan perubahan yang berlaku pada sejarah media sosial. Kajian jenis ini menyentuh kepada penembusan sosial yang lebih mendalam, terutamanya mengenai kesedaran media dan keberkaitan media. Kajian-kajian mediatisasi terdahulu dipilih untuk menjadi kerangka kepada penyelidik untuk mengemudi kajian yang dilakukan.

Menurut Pandian et al. (2020), generasi muda hari ini berdepan dengan dunia mediasi yang terbuka dengan peluang dan risiko ketika mereka berinteraksi dengan satu sama lain. Kaplan (2020) pula menjelaskan millennial, termasuk Generasi Z sering dikatakan tinggal di dalam gelembung media sosial tersendiri. Rentetan daripada itu, meletakkan mediasi sebagai asas kepada usaha untuk mendalami proses mediatisasi. Kajian Khadijah dan Ummu Syafiqah (2020) pula mendapati, Twitter membantu belia untuk menyuarakan suara mereka yang terabai dan sering disalah erti. Oleh itu, belia dilihat menganggap media sosial sebagai suatu kawasan selamat untuk belia menyuarakan pandangan masing-masing. Justeru itu, kajiankajian ini memperlihatkan kepentingan untuk melakukan netnografi untuk mendalami pengalaman peminat terutamanya peminat generasi $Z$. 
PERKEMBANGAN TEKNOLOGI MEDIA, GELOMBANG KOREA DAN PEMINAT

Fenomena gelombang Korea menerangkan tentang penerimaan peminat global terhadap produk budaya Korea Selatan. Produk budaya Korea pula, membawa maksud sebagai suatu hiburan ringan, yang pada awalnya diminati oleh golongan wanita suri rumah dan juga golongan remaja (Kim, 2011). Lim (2013) pula mendapati ahli komuniti K-Pop di Malaysia selalunya berkomunikasi dalam kalangan mereka melalui media sosial seperti di Twitter tentang acara akan datang, barangan terbaru dan juga menggunakan Facebook untuk berhubung dengan kelab dan komuniti peminat K-Pop yang lebih besar di seluruh dunia. Jung dan Shim (2014) dalam kajian mereka yang dilakukan di Indonesia mendapati, muzik K-pop menjadi salah satu budaya popular yang diedarkan secara dinamik di pasaran pop global melalui rangkaian sosial. Ini sejajar dengan apa yang dikatakan oleh Kozinet (2002) iaitu, keputusan membeli dan penggunaan di bincang serta diperdebatkan dalam komuniti dalam talian dan ini memerlukan penyelidikan yang mempunyai ketelitian untuk mengumpul dan mentafsir data dalam konteks yang lebih mencabar. Sekali gus memperlihatkan perlunya kajian dalam talian dijalankan untuk mendapatkan penemuan terbaru dan boleh memahami generasi belia masa ini.

Selain gelombang Korea, terma Hallyu turut membawa maksud yang sama di dalam perbincangan global tentang fenomena budaya popular ini. Fenomena gelombang Korea menghuraikan tentang peningkatan dalam penglihatan dan penerimaan antarabangsa terhadap produk budaya Korea, bermula di Asia Timur pada tahun 1990-an dan berterusan sehingga di Amerika Syarikat, Amerika Latin, Timur Tengah dan beberapa bahagian Eropah (Korean Culture and Information Service, 2011). Berdasarkan kajian-kajian terdahulu, produk gelombang Korea terdiri daripada terbitan bersiri televisyen dan muzik pop ( $K$-Pop), filem Korea dan genre muzik lain yang juga sebahagian daripada fenomena ini (Kim, 2015; Doobo Shim, 2017; Jang \& Paik, 2012; Kim, 2011; Korean Culture and Information Service, 2011; Nor Hasimah \& Zaharani, 2011; Ravina \& Mark, 2009). Secara ringkasnya, gelombang Korea boleh difahami sebagai segala bentuk produk budaya Korea termasuk muzik pop, drama, filem dan permainan video yang mengetengahkan selebriti mereka kepada khalayak sasaran. Shim (2017) mengembangkan lagi istilah ini dengan menjelaskan selepas awal tahun 2010, gelombang Korea juga termasuk semua genre budaya Korea termasuk makanan, minuman, fesyen, alat solekan, dan sebagainya lagi. Kajian-kajian lepas mengenai gelombang Korea membuktikan skop terhadap produk budaya Korea perlu diluaskan lagi untuk mendalami fenomena sosial ini.

Gelombang Korea telah melalui beberapa fasa yang dibahagikan kepada tiga fasa utama iaitu Hallyu 1.0, Hallyu 2.0 dan Hallyu 3.0. Fasa Hallyu 1.0 menitikberatkan eksport produk budaya ke Asia Timur di antara lewat 1990-an sehingga 2007 (Jin, 2012; Kim, 2015). Ketika tempoh ini, organisasi budaya Korea turut mengembangkan pelbagai produk kebudayaan mereka dan memperluaskan pengeksportan ke luar negara terutamanya di Asia Timur dan Asia Tenggara. Perluasan eksport ke luar negara telah menyumbang kepada peningkatan populariti program televisyen terutamanya drama bersiri dan hanya pada lewat tahun 1990-an, Korea Selatan muka mengeksport filem-filem terbitan mereka ke Asia Timur (Jin, 2012).

Seterusnya bagi Hallyu 2.0 pula menjelaskan bahawa, pada pertengahan 2000-an produk budaya Korea berpusat kepada kumpulan muzik yang dikenali sebagai kumpulan idola Korea (K-Pop Idol) (Jin, 2012; Kim, 2015). Kumpulan idola Korea diperkenalkan kepada dunia melalui internet dan laman sesawang kemudiannya, disebarkan oleh rangkaian media sosial 
dalam kalangan para peminat muzik Kpop . Kegilaan Kpop merupakan suatu trend yang telah mencapai seluruh dunia dan bukan hanya di Asia Timur (Kim, 2015; Jin, 2012). Seo et al. (2013) turut menyatakan bahawa, industri teknologi maklumat Korea yang mapan dan perkembangan media sosial memberi kelebihan kepada industri budaya untuk menarik perhatian khalayak global. Selain itu, YouTube memainkan peranan penting sebagai pemangkin dalam mempromosikan gelombang Korea ini. Kepentingan Hallyu 2.0 telah melanjutkan dari budaya Kpop kontemporari ke dalam budaya tradisional seperti Hangul (bahasa Korea), Hansik (makanan) Hanbok (pakaian tradisional) Hanok (rumah tradisional Korea) (Kim, 2015; Nor Hashimah \& Zaharani, 2011). Selaras dengan itu, Hallyu 2.0 juga telah membawa kepada pembangunan Hallyu 3.0 dan hanya selepas 3 tahun, Hallyu 3.0 (K-budaya) menjadi sangat popular. Peningkatan populariti budaya Korea di dalam laman sesawang telah menyebabkan China mengeluarkan peraturan untuk mengawal kemasukan produk budaya Korea dalam talian dan pada masa yang sama, sentimen anti-Korea turut berkembang di Jepun.

Selain dari tiga fasa utama fenomena gelombang Korea, Kim (2015) turut mengetengahkan isu Hallyu 4.0 yang melihat kepada peranan dan hak selebriti Korea itu sendiri. Perkara ini merujuk kepada hak publisiti selebriti, di mana syarikat atau jenama produk telah menggunakan nama atau suara selebriti dan mengaitkan mereka dengan produk tertentu. Isu mengenai hak publisiti merupakan satu isu penting disebabkan oleh minat dan perasaan peminat di seluruh dunia yang mendorong kepada peningkatan penjualan produk. Tambahan lagi, syarikat-syarikat penjualan menyasarkan perasaan peminat ini sebagai satu perkara penting untuk menaikkan dan mengekalkan imej bintang Korea. Perkara ini menjelaskan tentang kepentingan dalam penggunaan dan melindungi hak publisiti bintang Korea di dalam produk budaya mereka. Kepentingan ini sebagai contohnya melalui penyisipan produk atau Product Placement dan produk tajaan (Endorsement) oleh selebriti tertentu (Kim, 2015; Nor Hashimah \& Zaharani, 2011) yang mampu menjana pendapatan yang tinggi disebabkan oleh permintaan dalam kalangan peminat juga tinggi. Kajian-kajian ini membuktikan bahawa gelombang Korea sebagai suatu fenomena sosial yang perlu dikaji dengan lebih mendalam. Selaras dengan itu, perlunya lebih banyak kajian untuk memperlihatkan fasa terkini gelombang Korea dan pengaruh mereka kepada peminat.

Kajian Lim (2013) mendapati peminat daripada komuniti gelombang Korea turut mengatur pertemuan luar talian melalui perbincangan dalam talian. Hasil kajian beliau turut memperlihatkan kepada peningkatan dalam populasi remaja yang menggunakan media sosial terutamanya untuk menggerakkan belia yang memiliki minat dan pemikiran yang sama untuk terlibat dengan acara luar talian seperti flashmobs, pesta jalanan dan pertandingan menari Kpop. Oleh itu, tidak menghairankan apabila kumpulan peminat gelombang Korea sentiasa berkembang dalam dunia maya. Perkara ini juga memperlihatkan forum internet dan media sosial menjadi tempat utama untuk kumpulan peminat berkumpul dan berinteraksi. Kajian ini mengetengahkan bagaimana aktiviti peminat itu saling berkait sama ada melalui perbincangan dalam media sosial atau menjalankan aktiviti rasmi di dunia sebenar. Pengkaji melihat perlunya kajian lanjutan untuk melihat komuniti dalam talian ini dan sejauh mana ia telah berkembang dan mempengaruhi kehidupan harian peminat gelombang Korea.

Rentetan itu, perkembangan media dan teknologi dilihat telah mengubah hubungan antara peminat dengan produk gelombang Korea dan meningkatkan lagi kebergantungan belia terhadap media baharu (Nurul Akqmie et al., 2019). Sebagai contoh, media sosial kini menjadi sumber rujukan utama untuk mendapatkan informasi mengenai produk gelombang 
Korea, di samping membina komunikasi yang lebih luas. Nazra Aliff dan Abdul Latiff (2020) pula mengatakan kemajuan teknologi yang canggih pada masa ini mendorong sesebuah budaya untuk tersebar dengan lebih meluas ke serata dunia contohnya, minat mendalam yang dipamerkan oleh rakyat Malaysia telah membawa kepada pelbagai rancangan dan drama Korea telah diadaptasi dalam konteks tempatan. Dengan tumpuan kepada masyarakat di era digital, pengkaji beranggapan perlu dititik beratkan tentang bagaimana perkembangan dan kemajuan media dan teknologi untuk memahami keadaan peminat gelombang Korea pada masa ini. Perkara ini mampu memberi satu perspektif baru dalam memahami budaya peminat dan juga generasi belia pada masa kini.

\section{PERKEMBANGAN MEDIA DAN TEKNOLOGI DALAM PENYEBARAN GELOMBANG KOREA DI MALAYSIA}

Rajah 1 dibina oleh Kim Bok-Rae pada tahun 2015, untuk menerangkan fasa-fasa gelombang Korea dan ramalan beliau terhadap fenomena sosial ini. Pengkaji melihat kita kini berada di fasa ketiga iaitu, di era ramalan Kim Bok-Rae.

\begin{tabular}{|c|c|c|c|}
\hline & Hallyu 1.0 & Hallyu 2.0 & Hallyu 3.0 \\
\hline Tempoh & $1995 \sim 2005$ & 2006- sehingga sekarang & Ramalan pada masa akan datang \\
\hline $\begin{array}{l}\text { Kawasan } \\
\text { Penyebaran }\end{array}$ & Asia (China dan Jepun) & $\begin{array}{l}\text { Asia, Amerika Utara dan } \\
\text { Eropah }\end{array}$ & Seluruh dunia \\
\hline Sasaran & $\begin{array}{c}\text { Kandungan media(K-Drama dan } \\
\text { filem) } \\
\text { (berorentasikan produk) }\end{array}$ & $\begin{array}{c}\text { Idola - Idola K-Pop } \\
\text { (Berorentasikan Selebriti Korea) }\end{array}$ & $\begin{array}{c}\text { Kepelbagaian Genre } \\
\text { (Berorientasikan Selebriti dan } \\
\text { pencipta Jenama) }\end{array}$ \\
\hline Kes & $\begin{array}{c}\text { "What is Love? (1992)," } \\
\text { "Winter Sonata (2002), My Sassy } \\
\text { Girl (2001)" "Jewel in the Palace } \\
\text { (2003-2004)," HOT (kumpulan), } \\
\text { Boa (penyanyi). }\end{array}$ & $\begin{array}{c}\text { Girls' Generation, Kara, } \\
\text { Shinee, 2PM, and Big Bang }\end{array}$ & \\
\hline $\begin{array}{c}\text { Pembahagian } \\
\text { awal }\end{array}$ & Masyarakat Korea diluar negara & $\begin{array}{c}\text { Edaran dalam talian } \\
\text { (YouTube) }\end{array}$ & Media Sosial \\
\hline Media & Video, CD, penyiaran & Internet, persembahan fizikal & Merentas Media \\
\hline Ketahanan & $\begin{array}{l}\text { Dari beberapa bulan ke tahun } \\
\text { (Winter Sonata) }\end{array}$ & $\begin{array}{l}\text { Selama Beberapa Tahun } \\
\text { (Girls' Generation) }\end{array}$ & Selama Beberapa Dekad \\
\hline Kerterarahan & $\begin{array}{c}\text { Mengalihkan pandangan dunia } \\
\text { kepada Korea (Pelancongan) }\end{array}$ & $\begin{array}{l}\text { Perluaskan persembahan } \\
\text { ke luar negara }\end{array}$ & $\begin{array}{l}\text { Ke seluruh dunia } \\
\text { (Di anggap sebagai } \\
\text { arus perdana) }\end{array}$ \\
\hline
\end{tabular}

Sumber: Kim Bok-Rae (2015, pg: 158)

Rajah 1: Fasa Gelombang Korea (Hallyu) oleh Kim Bok-Rae (2015)

Dengan menggabungkan penelitian kajian-kajian lepas dan mengadaptasi carta yang dibina oleh Kim Bok-Rae, pengkaji menghasilkan Rajah 2 yang menjelaskan tentang fasa-fasa gelombang Korea di Malaysia. 


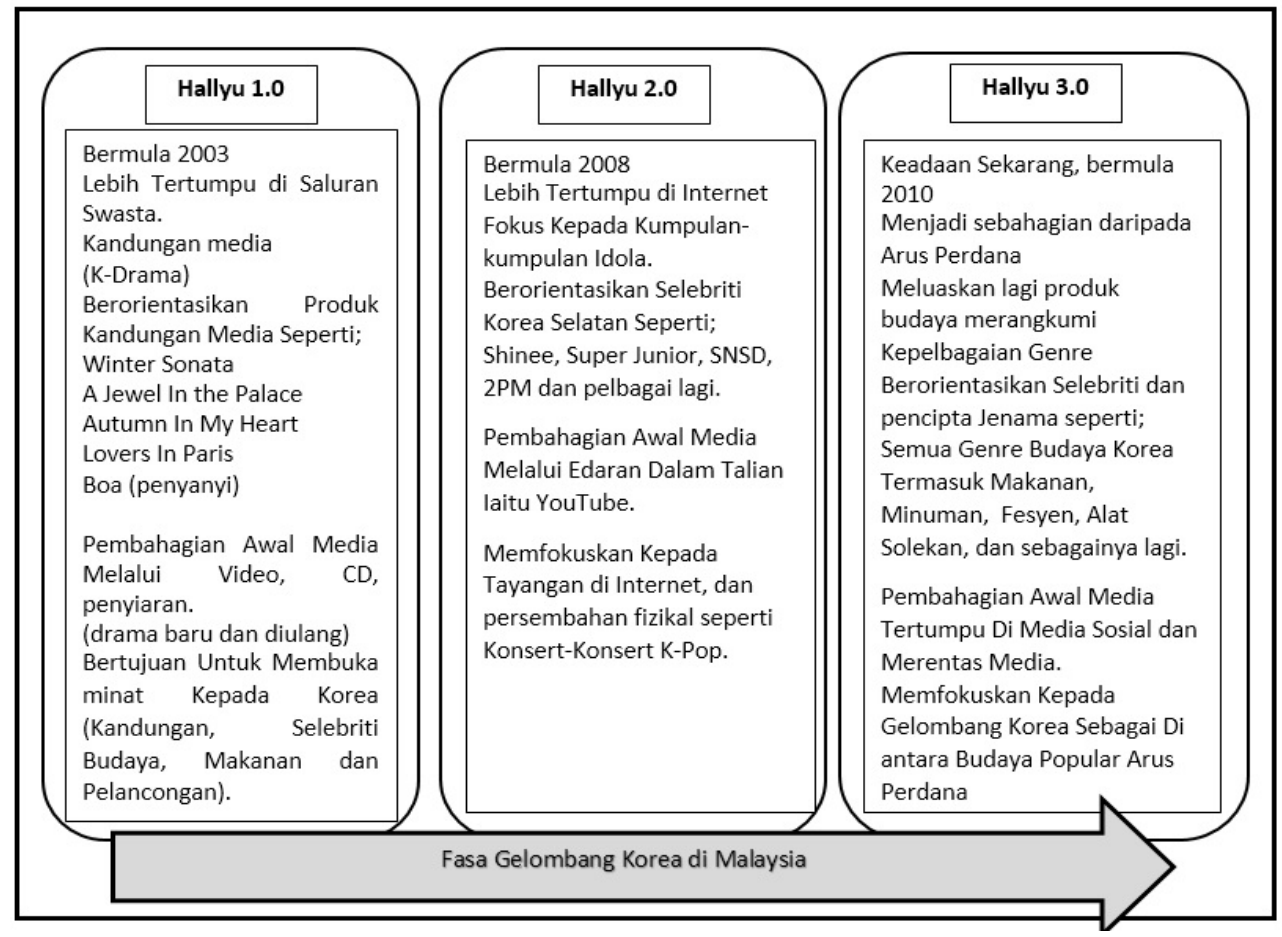

Rajah 2: Fasa Gelombang Korea (Hallyu) di Malaysia

Berdasarkan pemerhatian pengkaji, keadaan fenomena ini terutamanya di Malaysia, memenuhi ciri-ciri yang telah diramal oleh Kim Bok-Rae. Fenomena gelombang Korea bermula di Malaysia seawal 2003, iaitu menerusi K-drama Winter Sonata di saluran NTV7 (Nor Hasimah \& Zaharani, 2011; Norbaiduri \& Siti Sakinah, 2016). Pada awalnya drama-drama seperti Autumn in My Heart, Jewel in the Palace dan pelbagai lagi menarik minat khalayak dalam kalangan suri rumah sehinggakan diulang tayang sebanyak tiga kali (Nor Hasimah \& Zaharani, 2011). Hal ini memperlihatkan populariti drama Korea mendapat perhatian saluran televisyen di Malaysia dan sekali gus, mengukuhkan fenomena gelombang Korea di Malaysia. Kajian-kajian ini juga membuktikan bermula pada tahun 2005, Malaysia telah menerima produk budaya Korea dengan stabil dan selari dengan hujahan Kim (2015) yang merujuk kepada fasa Hallyu 1.0.

Selain itu, kajian Nor Hasimah dan Zaharani (2011) turut mendapati drama Jewel in the Palace juga membawa pengetahuan tentang makanan dan budaya Korea Selatan dan telah diterima baik oleh rakyat Malaysia. Kemasukan K-Pop pula pada tahun 2008, melalui YouTube membawa kepada penerimaan belia dan pada masa yang sama, mendorong belia mengadaptasi nilai fesyen dan mempelajari bahasa Korea (Jung \& Shim, 2014; Lim, 2013). Pada awalnya, kumpulan-kumpulan idola Korea Selatan yang popular di Malaysia adalah seperti Shinee, Super Junior, SNSD, 2PM. Bermula pada awal 2010, istilah gelombang Korea mula dikembangkan lagi dengan mengambil kira lebih banyak produk-produk budaya Korea Selatan termasuk makanan, minuman, fesyen, tatarias dan pelbagai lagi (Shim 2017).

Inovasi dan perkembangan teknologi komunikasi dunia telah membawa perubahan dalam kehidupan masyarakat terutamanya dalam penggunaan media dan untuk berkomunikasi. Dengan wujudnya internet, digabungkan dengan kewujudan media sosial dan penggunaan telefon pintar telah membawa kepada perubahan bagaimana manusia melakukan aktiviti harian. Hal ini yang menyumbang kepada perubahan antara generasi $Z$ dengan generasi sebelum ini. Penerimaan dan penggunaan kandungan media yang semakin 
meningkat disebabkan oleh akses yang lebih mudah dan berpelbagai. Akses ini pula lebih luas, lebih murah dan ada yang percuma tanpa sebarang sekatan. Ini menampakkan keadaan fenomena gelombang Korea di Malaysia kini berada di fasa ketiga dan kemuncak fenomena ini.

\section{METODOLOGI KAJIAN}

Kajian ini menggunakan kaedah kualitatif dengan memilih teknik pengumpulan data netnografi untuk meneliti trend dan isu yang berkaitan dengan fenomena gelombang Korea. Disebabkan hampir semua acara fizikal dibatalkan, pemerhatian dalam talian menjadi pilihan yang tepat dalam merungkai fenomena gelombang Korea di kala pandemik global.

Netnografi merupakan teknik mengutip data yang memfokuskan kepada komunikasi komuniti dalam talian dan ruang media sosial (Costello, Mcdermott, \& Wallace, 2017; Kozinets, 2010, 2002, 2015). Menurut Ferreira (2015) netnografi juga disebut sebagai etnografi maya yang membahaskan tentang bagaimana pengkaji etnografi terlibat secara mendalam di ruang siber dan pada masa yang sama, peka terhadap komunikasi dalam internet. Kajian ini dikembangkan berdasarkan pemahaman terhadap internet sebagai satu budaya dan artifak budaya.

Addeo et al. (2019) menjelaskan bahawa, kajian netnografi tidak hanya terhad kepada analisis individual atau terpencil mengenai mesej-mesej yang dikirim di internet, tetapi lebih kepada meneroka interaksi komunikasi yang berterusan dan berulang melalui saluran dan teknologi komputer. Kajian ini turut bergantung kepada topik dan tujuan penyelidikan, komuniti yang dianalisis sama ada dalam kalangan blog, forum, rangkaian sosial media, perbualan, dunia maya dan sebagainya lagi.

Acara yang dipilih untuk kajian ini adalah berdasarkan sampel kriteria (criterion) atau sampel bertujuan (purposive). Sampel bertujuan ini menjelaskan bahawa informan, subjek atau unsur-unsur yang dipilih berdasarkan ciri-ciri atau sifat tertentu (Wimmer \& Dominick, 2014). Zainudin Awang (2010) menyatakan bahawa, sampel yang dipilih adalah berdasarkan pertimbangan pengkaji terhadap ciri-ciri yang diperlukan untuk dimasukkan dalam kajian. Lindlof dan Taylor (2011) menjelaskan bahawa, pengkaji membuat keputusan untuk memilih orang atau aktiviti, acara, tapak dan tetapan berdasarkan kriteria telah ditetapkan oleh penjelasan mengenai teori yang dipilih atau penerangan umum tentang subjek yang ingin dikaji. Data-data dapatan kajian kemudiannya dianalisis menggunakan perisian Nvivo-12 dan melalui proses analisis tematik.

\section{DAPATAN KAJIAN}

Disebabkan oleh pandemik Covid-19, pemerkasaan penggunaan teknologi baharu mampu memberi nafas baru kepada hubungan artis Korea dan peminat mereka. Artis dan agensi pengurusan juga perlu berusaha untuk mengekalkan kumpulan peminat mereka sebagai contoh, melalui sesi penstriman, penayangan semula konsert lama sehingga ke panggilan video peribadi. K-Pop telah berkembang dengan lebih cepat dan skala yang lebih besar di kala penularan pandemik global (Yoon, 2020). Artikel ini tertumpu kepada dua jenis acara iaitu, konsert dan acara rasmi Gelombang Korea. 


\section{a. Konsert dan Acara Rasmi Gelombang Korea}

Penelitian terhadap fenomena gelombang Korea di Malaysia mendapati majoriti acara hiburan dari Korea Selatan telah ditunda dan dibatalkan seawal bulan Februari 2020. Di antara konsert-konsert mega yang terbabit adalah seperti Seventeen World Tour yang dirancangkan pada 22 Februari 2020, Super Junior World Tour pada 1 Mac 2020, Kim Jae Joong pada 14 Mac 2020 dan pelbagai lagi. Syarikat terpaksa membuat pengumuman pembatalan dan memulakan proses pembayaran balik bagi tiket-tiket yang sudah terjual. Hal ini mendatangkan pelbagai reaksi bagi peminat dan juga artis. Kekecewaan dilihat bukan sahaja bagi pihak peminat yang telah membeli tiket, tetapi kepada artis dan syarikat pengurusan yang telah mengeluarkan duit untuk memastikan persiapan konsert berlangsung dengan lancar.

Ramai peminat meluahkan perasaan tidak puas hati di laman-laman media sosial terutamanya di Twitter dan ini mendapat perhatian daripada pihak artis dan pengurusannya. Pada 14 Februari 2020, kumpulan Winner mengadakan konsert secara percuma di dalam talian dengan menggunakan aplikasi VLive. VLive adalah sejenis aplikasi penstriman video dalam talian di Korea Selatan, yang membolehkan para artis untuk berkongsi video dan berhubung dengan peminat mereka di satu dunia. Aplikasi ini sering digunakan oleh para artis untuk berbicara bersama peminat atau berkongsi tentang perkembangan dan jadual mereka. Setiap artis mempunyai saluran tersendiri dan berfungsi seperti satu ruang persendirian yang lebih bersifat intim dan peribadi di antara peminat dan artis yang mereka gemari.

Disebabkan oleh Covid-19, kumpulan Winner telah membatalkan dua buah konsert mereka iaitu, di Singapura pada 8 Februari 2020 dan konsert "Encore" di Seoul pada 14 Februari 2020. Mereka telah pun menggantikan dengan konsert dalam talian yang dinamakan "Winner Cross Special Live" (https://www.vlive.tv/video/175019/Replay-WINNER-CROSSSPECIAL-LIVE). Konsert dalam talian ini, berlangsung selama hampir dua jam dan dijadikan sebagai penutup untuk konsert jelajah Cross mereka. Konsert dalam talian tersebut telah berlangsung mengikut format konsert sebenar dan dinyanyikan secara langsung. Selain itu, mereka juga sekali lagi memilih VLive untuk membuat majlis pelancaran album terbaru mereka yang berjudul "Remember" (https://www.vlive.tv/video/181920/Replay-WINNERCOMEBACK-LIVE-Hold-a-Remember-Party). Perbezaannya hanyalah kepada keberadaan khalayak yang merentas ruang sempadan fizikal dan masa kerana boleh dilayari melalui internet.

Selain Winner, untuk meraikan ulang tahun ke-15, kumpulan duo TVXQ turut memilih aplikasi VLive untuk melangsungkan konsert Beyond the $T$ pada 24 Mei 2020. Persembahan mereka telah meraih lebih 200 juta tanda hati di aplikasi ini, yang memperlihatkan sokongan yang masih kuat dalam kalangan peminat mereka (https://www.vlive.tv/video/190574). Pihak agensi atau syarikat pengurusan artis Korea, mula membina pendekatan baru untuk menjana pendapatan seperti menggunakan mata wang khusus untuk aplikasi terbabit. Sebagai contoh, SM Entertainment telah melangsungkan konsert SuperM, Beyond The Future Live pada tarikh 26 April 2020 (https://www.vlive.tv/video/186081). Peminat perlu membayar sebanyak 1500 VLive coins yang bersamaan dengan RM114.99 untuk menonton persembahan mereka. Kewujudan mata wang dalam talian ini memberikan pengalaman baharu proses jual beli tiket konsert dalam kalangan peminat gelombang Korea.

Selari dengan itu, YouTube turut menjadi saluran pilihan untuk artis memaparkan kandungan secara percuma untuk peminat mereka. Artis-artis Hip Hop dari syarikat pengurusan AOMG mengadakan AOMG Quarantine Nonstop Live pada 12 April 2020 di 
saluran YouTube rasmi mereka (https://www.youtube.com/watch?v=20vZMEKKmM0 https://www.youtube.com/watch?v=yrk8WhCP8Ns) dan kemudiannya, turut berkongsi di laman Instagram masing-masing. Syarikat pengurusan Big Hit Entertainment yang menguruskan kumpulan BTS turut menayangkan kesemua konsert-konsert terdahulu mereka secara percuma di YouTube. Penayangan ini berlangsung secara dua hari berturut-turut iaitu pada 18 dan 19 April 2020. Acara dikenali sebagai di panggil sebagai Bang Bang Con (https://www.youtube.com/user/BANGTANTV).

YouTube juga menjadi pilihan untuk YG Entertainment memaparkan dokumentari White Night oleh Taeyang dari kumpulan BigBang bermula pada 18 Mei 2020 (https://www.youtube.com/channel/UCZw-C7fNfs018R1FzIKnlaA). Saluran YouTube turut menjadi pilihan dalam penayangan rancangan realiti seperti:

- The Return of Superman (https://www.youtube.com/hashtag/thereturnofsuperman),

- K-POP Lyrics Helper (https://www.youtube.com/watch?v=wv3zrbY5pll),

- BangTan Bomb (https://www.youtube.com/watch?v=X51El1Jq7vg), dan pelbagai lagi.

Pada 14 Jun 2020 pula, berlangsungnya konsert BTS, Bang Bang Con The Live menerusi aplikasi Weverse. Aplikasi Weverse pula merujuk kepada platform komuniti peminat dalam talian untuk berhubung dengan selebriti Korea Selatan terutamanya di bawah syarikat pengurusan BigHit Entertainment. Peminat masih melalui pengalaman yang sama dengan menghadiri konsert fizikal iaitu, mereka perlu terlebih dahulu membeli tiket di aplikasi terbabit. Peminat akan terlebih dahulu mendapat perincian untuk proses daftar masuk untuk menonton konsert ini di peranti pilihan mereka. Tiket-tiket berharga di antara 26 USD (untuk mereka yang memiliki keahlian Global Official Fan Club Army) dan 35 USD bagi khalayak umum (https://www.usbtsarmy.com/latest-updates/bangbangcon-the-live).

Sebelum berlangsungnya konsert, syarikat pengurusan telah membuat hantaranhantaran di laman media rasmi mereka tentang persediaan untuk peminat. Hantaran oleh syarikat pengurusan memberi penerangan untuk melancarkan proses penontonan konsert dalam talian termasuk jenis peranti komunikasi yang bersesuaian untuk menerima siaran langsung, peminat turut memerlukan kelajuan internet $20 \mathrm{Mps}$ ke atas dan mereka lebih menggalakkan peminat untuk menggunakan Wi-Fi apabila mengakses kepada konsert ini. Mereka juga mengingatkan para peminat untuk tidak merekod, berkongsi ataupun mengedit sebarang kandungan yang disiarkan. Konsert ini berlangsung selama satu jam 30 minit dan mengikut format konsert fizikal seperti senarai lagu, koreografi, kostum dan juga tetapan lantai dan cahaya.

Aplikasi TikTok juga mendapat tempat dalam mengadakan acara secara langsung di dalam talian. Sebagai contoh, konsert TikTok Stage With HipHopPlaya pada 27 Mei 2020 (https://www.tiktok.com/@hiphopplaya?lang=en) dan juga majlis Baeksang Arts Awards pada 5 Jun 2020. Majlis anugerah seni Baeksang ini adalah suatu acara penting dalam menghargai kecemerlangan dalam industri filem dan drama. Majlis anugerah ini turut disiarkan di aplikasi VLive dan juga laman rasmi saluran JTBC.

Selain konsert dan majlis-majlis rasmi, pandemik global Covid-19 turut mengganggu acara-acara istimewa di antara artis dan peminat mereka. Acara-acara yang dinantikan seperti sambutan tamat latihan ketenteraan dan majlis bertemu peminat terpaksa ditunda dan diubah. Kebanyakan memilih untuk mengadakan acara ringkas di aplikasi VLive sahaja. Namun, kumpulan Winner sekali lagi mengambil inisiatif lain untuk memperlihatkan penghargaan kepada peminat mereka. Selepas pelancaran album terbaru mereka, kumpulan 
Winner mengumumkan bahawa mereka akan melakukan sesi bertemu peminat yang ringkas dan hanya beberapa orang peminat sahaja yang terpilih. Mereka akan membuat panggilan video kepada peminat menerusi aplikasi FaceTime, Line dan KakaoTalk (https://www.vlive.tv/video/186283). Mereka akan menelefon dan meluangkan masa selama lima minit untuk beramah mesra dengan para peminat. Pengkaji mendapati, ramai peminat yang merekod dan berkongsi pengalaman ini di akaun media sosial masing-masing.

Apa yang membezakan acara fizikal dengan acara dalam talian ini adalah, selain daripada harga tiket yang lebih murah, para artis boleh berinteraksi bersama peminat dengan membaca komen-komen yang ditinggalkan di ruangan komen, dan menjawab persoalan yang ditanya oleh peminat secara langsung. Selain itu, lebih banyak jumlah penonton yang menonton dan ia tidak terhad kepada bilangan ruangan yang disediakan. Apabila dunia dilanda pandemik Covid-19, pengkaji mendapati selain maklumat-maklumat yang sering dikongsi, terdapat penambahan dari segi bagaimana Korea Selatan mengawal penularan Covid-19, inisiatif yang diambil dan langkah-langkah keselamatan yang telah dijalankan di Korea Selatan. Perkongsian kesedaran tentang Covid-19 dijalankan dalam bentuk pesanan perkhidmatan awam dan dikongsikan melalui akaun peribadi selebriti contohnya "WINNER Covid-19 Message" (https://www.vlive.tv/video/182155). Walaupun Korea Selatan masih menutup sempadan negara, kandungan media dan acara rasmi seperti konsert, pertemuan peminat, majlis anugerah dan sebagainya masih lagi giat dijalankan. Namun, promosi yang dijalankan lebih berfokus dalam kalangan komuniti peminat dan juga dalam talian.

\section{PERBINCANGAN}

Menurut Hepp (2009) kajian teori mediatisasi dan budaya yang menggunakan analisis kualitatif perlu melihat bagaimana penyebaran sesuatu media berkait rapat dengan perubahan budaya harian. Untuk memahami proses ini, fokus harus diberi kepada apa yang disebutkan oleh beliau sebagai kuasa pengacuan media. Kuasa pengacuan media merujuk kepada bagaimana media memberikan suatu tekanan yang membentuk cara manusia berkomunikasi. Perkembangan teknologi media komunikasi tanpa disedari bukan hanya mengubah cara bagaimana masyarakat berhubung tetapi juga mempengaruhi budaya aktiviti harian manusia. Sebagai contoh, penggunaan telefon bimbit membolehkan peminat terus kekal dalam hubungan komunikasi dengan artis selain melayari persembahan di dalam aplikasi maya.

Sejak wabak coronavirus-19 diumumkan sebagai satu pandemik global, ini telah mengubah kehidupan manusia dari segi ekonomi, sosial dan psikologi (Prayoga, 2020). Kajian ini mendapati walaupun dunia dilanda pandemik global, penerimaan dan penggunaan (consumption) produk budaya Korea dalam kegiatan harian masih lagi berterusan. Contohnya, proses membeli belah dan penonton filem serta drama Korea baru masih berterusan secara dalam talian. Pengalaman peminat masih lagi diteruskan melalui secara maya melalui aplikasi dalam peranti komunikasi media seperti telefon bimbit, komputer dan juga tablet. Perkara ini membuktikan apa yang dikatakan oleh Schulz (2004), di mana media berperanan dalam melanjutkan aktiviti manusia. Pembelian dalam talian membolehkan aktiviti pembelian dijalankan bila-bila masa tanpa mengira lokasi juga. Walaupun berlakunya penutupan sempadan, proses membeli belah masih lagi berterusan. 
Selain itu, disebabkan oleh pandemik global ini, kesemua acara melibatkan orang ramai telah dibatalkan dan tidak dibenarkan. Ini membuka ruang kepada lebih banyak aplikasi dalam talian diwujudkan dan juga membuka pasaran yang lebih luas kepada mereka yang meminati produk gelombang Korea. Kajian ini juga mendapati pelbagai aplikasi wujud sebagai contoh TikTok, VLive, Weverse dan pelbagai lagi yang menggantikan acara fizikal namun tetap memberikan pengalaman menghadiri konsert dan acara rasmi. Dengan hanya melihat melalui telefon bimbit, mereka dibawa menonton konsert di peringkat antarabangsa secara langsung dengan penonton dari pelbagai ceruk dunia. Jika sebelum ini, penonton hanya berada di sesuatu lokasi yang telah ditetapkan dan jumlah juga terhad, pembukaan kepada penonton dalam talian membolehkan lebih ramai peminat menonton tanpa mengira sempadan dan waktu.

Ini memperlihatkan media itu bukan hanya berperanan untuk menggantikan sesetengah aktiviti manusia tetapi juga meluaskan ketercapaian (accessibility) terhadap sesuatu produk rancangan ataupun acara langsung. Penelitian ini juga membuktikan bagaimana perkembangan teknologi media komunikasi berperanan dalam melakukan pembaharuan dan pengalaman baharu aktiviti manusia yang berkaitan hiburan. Kajian ini membuktikan bagaimana perkembangan teknologi itu meningkatkan proses komunikasi masyarakat dari masa ke semasa. Ini sejajar dengan apa yang dikatakan oleh Turner (2016) tentang bagaimana masyarakat kini telah memasuki sesuatu kawasan yang berbeza daripada masyarakat sebelum ini. Perubahan kecil dalam aktiviti harian mungkin berlangsung tanpa disedari oleh manusia dan ini diolah oleh teori mediatisasi dan budaya.

Pengkaji mendapati informasi mengenai konsert, drama dan juga produk-produk budaya lain sering kali dikongsi dalam kalangan sekelompok peminat yang sama. Orang luar dari kumpulan ini, mungkin tidak mempunyai akses kepada maklumat yang sama. Sebagai contoh, kumpulan peminat BTS Malaysia Swag Army menjadi pengampang maklumat (Gatekeeper) untuk berkongsi informasi mengenai Bang Bang Con kepada ahli mereka. Ini selari dengan apa yang dikatakan oleh Lim (2013) serta Jung dan Shim (2014), tentang bagaimana ahli komuniti berkomunikasi dalam kalangan mereka melalui media sosial masingmasing. Walaupun artis ini mempunyai agensi dan syarikat yang mengelola aktiviti mereka, ahli komuniti sentiasa membuat semakan di antara satu sama lain. Ini diterangkan oleh Kozinet (2002) yang merujuk kepada keputusan pembelian dan penggunaan sesuatu produk dibincangkan dalam komuniti dalam talian. Ini memperlihatkan pemilihan metodologi kajian ini sangat bersesuaian dengan subjek kajian.

Generasi Z sebagai fokus utama kajian ini, memperlihatkan individu celik teknologi memainkan peranan yang besar sebagai pemangkin dalam menghubungkan perkembangan teknologi dengan produk budaya gelombang Korea. Mereka menggunakan teknologi media untuk membina rangkaian mereka tersendiri tanpa mengira sempadan dan perbezaan waktu kerana berkongsi maklumat mengenai produk budaya yang mereka minati dan berkongsi kisah selebriti kesayangan mereka. Pandian et al. (2020) mengatakan bahawa, melalui dunia digital, generasi muda membina naratif dan gambar yang menjelaskan tentang persepsi dan kepercayaan mereka terhadap hubungan, pilihan dan keputusan yang mereka ambil dalam tugasan harian mereka. Perkara ini menyebabkan generasi ini mula berurusan dengan pasaran yang khas terus dari Korea Selatan. Produk-produk ini tidak perlu melalui sebarang halangan untuk menemui khalayak sasaran masing-masing dan mampu mengekalkan kemandirian gelombang Korea, walaupun dunia berhadapan dengan oleh pandemik global. Harus diingatkan bahawa, adalah penting untuk menitik beratkan kesedaran tentang 
ancaman yang dibawa oleh arus teknologi ini terutamanya apabila lebih banyak transaksi dan pertukaran maklumat yang berlaku pada hari ini berbanding pada generasi sebelum ini. Ancaman boleh dilihat dari segi apa yang dikatakan oleh Pandian et. al (2020) sebagai contohnya, para peminat berpotensi untuk berhadapan dengan risiko terutamanya dalam menerima lambakan kandungan media dan juga menjadi peminat obsesif dan semakin hilang sempadan realiti dalam kehidupan mereka.

Kajian ini memberi penekanan kepada peminat-peminat dalam kalangan generasi $Z$ yang mempunyai akses yang luas terhadap media dan teknologi. Majoriti mereka mempunyai tahap literasi media yang tinggi. Ini membuka ruang kepada mereka untuk mencari sendiri ruang dan kandungan yang mereka minat tanpa bergantung kepada media utama sematamata. Perhubungan dan perkongsian dalam komuniti dalam talian mereka juga mencipta satu ruang baharu yang boleh dilihat sebagai satu lanjutan kepada saluran media massa yang wujud di dunia. Media sosial dan komuniti yang dicipta di dalam talian ini membentukkan satu dunia maya dalam kalangan peminat generasi $Z$ ini. Kewujudan dunia maya ini membolehkan mereka sentiasa mencari akses baru, kandungan baru dan juga maklumat tentang gelombang Korea terutamanya terhadap acara maya.

Generasi $Z$ juga dilihat sebagai generasi celik media dan literasi media. Ini melengkapkan mereka dalam mencari sumber maklumat dengan lebih tepat dan mampu menapis maklumat-maklumat yang tidak benar di media sosial. Berbanding dengan acara fizikal, peminat tidak lagi mengadu mereka ditipu oleh pihak-pihak tertentu atau terbeli tiket yang salah di dalam talian. Proses pembelian untuk acara ini lebih telus dan secara langsung di aplikasi media. Ini membuktikan, peminat bukan hanya berpeluang untuk melihat artis dengan lebih dekat, mereka hanya membayar satu harga sahaja berbanding harga yang berbeza di acara fizikal. Acara maya juga lebih selamat untuk peminat terutamanya peminat belia. Kebolehan peminat generasi $Z$ dalam mengemudi diri di alam maya menyebabkan mereka lebih selamat dari sebarang ancaman keselamatan, dibandingkan terdedah dengan bahaya di dalam acara fizikal.

Pengalaman pengkaji ketika melakukan penelitian memperlihatkan bagaimana peminat generasi $Z$ yang terlibat dengan fenomena gelombang Korea ini memiliki dunia dan rangkaian mereka tersendiri. Dunia ini turut menggabungkan kehidupan fizikal dan kehidupan di dalam talian para peminat gelombang Korea. Hodkinson (2005) telah menjelaskan budaya belia ini bersifat kolektif dan Wiktorowicz (2004) pula menjelaskan bahawa suatu pergerakan dalam masyarakat terlebih dahulu memerlukan sumber dan struktur sebelum melakukan sesuatu secara kolektif. Kajian ini memperlihatkan bagaimana teknologi komunikasi media menjadi sumber utama kepada pergerakan dalam kumpulan peminat.

Sumber dan struktur ini mendorong kepada peminat-peminat untuk membuat keputusan dalam kehidupan mereka dalam mengerakkan kumpulan peminat ini. Rangkaianrangkaian dalam talian ini membolehkan mereka menjadi pengampang maklumat sendiri dan tidak hanya menerima maklumat. Peminat generasi $Z$ ini bukan hanya sebagai penerima maklumat atau penerima kandungan semata-mata. Mereka juga mempunyai kuasa untuk menyebarkan maklumat tentang gelombang Korea kepada rakan-rakan mereka dan berfungsi sebagai pemeriksa fakta serta sebagai pembuat kandungan. Ini bukan hanya membolehkan mereka kekal selamat tetapi memastikan ahli lain dalam komuniti juga selamat dan saling menjaga satu sama lain. Mereka juga berusaha untuk bergembira dan membantu sesama sendiri secara kolektif. 
Dunia ini bukan hanya merupakan satu lanjutan kepada media massa yang tersedia ada, tetapi mewujudkan satu platform perkongsian kandungan-kandungan Korea yang bebas dari kawalan dan kekangan yang telah wujud selama ini. Dunia ini juga melanjutkan proses komunikasi antara mereka yang melangkau sempadan fizikal, waktu dan juga norma-norma masyarakat. Ini bukan hanya menyokong apa yang dikatakan oleh Kaplan (2020) di mana mereka membina satu gelembung media sosial sendiri namun, gelembung ini juga membina satu dunia maya yang menjadi lanjutan kepada realiti sosial peminat generasi Z ini. Sekiranya sebelum ini peminat perlu menunggu pengumuman sama ada artis kegemaran mereka akan ke negara mereka atau tidak, atau peminat perlu mencari hotel dan pengangkutan untuk menghadiri acara yang melibatkan artis mereka, kini informasi tersebut berada di jari mereka.

Kini, mereka mempunyai akses terhadap acara-acara ini di ruang keselesaan masingmasing. Acara seperti konsert dan sebagainya ini, telah melangkau kekangan seperti lokasi, had masuk, harga tiket yang mahal, sempadan dan sebagainya. Peminat kini boleh menonton acara yang sama tanpa menghiraukan lokasi mereka. Mereka hanya perlu mengikut masa yang ditetapkan di Korea Selatan. Peminat boleh mengakses di mana sahaja mereka berada hanya berbekalkan internet dan peranti komunikasi. Jumlah penonton juga akan turut berganda berbanding sebelum ini.

Selain itu, dunia maya yang dibina oleh peminat gen $Z$ boleh dikaitkan dengan fahaman terhadap realiti maya (Virtual Reality) sebagai contoh, penggunaan avatar sebagai mewakilkan identiti peminat di dalam komuniti maya mereka. Menurut Conte (2019), kemasukan orang ramai secara mendadak ke ruang siber menyebabkan penggunaan avatar yang sebelum ini hanya dikaitkan dengan permainan maya, di adaptasi oleh orang ramai dalam dunia maya dan forum internet. Tambahan beliau lagi, adaptasi ini dilihat sebagai rampasan terbesar realiti maya iaitu terhadap kebolehannya untuk menjadi pengantaraan (mediasi) terhadap semua jenis media visual.

Avatar dan nama timangan merupakan suatu identiti yang mewakilkan individu untuk menghadiri acara maya. Peminat generasi $Z$ akan mencipta avatar yang mempunyai nilai sendiri kepada mereka dan mengambil masa untuk mencipta nama timangan. Kedua-dua perkara ini mempunyai makna sendiri kepada peminat dan juga mempunyai makna kepada artis yang mereka minati. la mungkin berkait dengan artis, memperlihatkan perasaan positif dan sokongan kepada artis. Kehadiran mereka melalui avatar dan nama timangan ini juga memberikan semangat kepada artis dan juga antara peminat. Ahli komuniti ini mungkin tidak pernah bertemu dan hanya mengenali satu sama lain berdasarkan avatar dan nama mereka.

Pembinaan dunia maya komuniti peminat gelombang Korea gen $Z$ dalam ruangan media sosial ini memperlihatkan bagaimana ruang media sosial, diberi nafas baru dan diberi pentakrifan berdasarkan perkembangan teknologi media komunikasi. Dunia maya turut memberikan kebebasan dan ruang selamat kepada peminat untuk mengekpresikan minat mereka terhadap produk budaya Korea. Pembinaan dunia maya dan perhubungan antara komuniti serta penggunaan media ini bukan hanya memberi definisi kepada kepentingan teknologi kepada manusia tetapi juga, membuatkan manusia semakin bergantung pada teknologi terutamanya teknologi media komunikasi. Peminat-peminat gen Z gelombang Korea ini memerlukan ruang baru media sosial dan peranti komunikasi untuk berada di dunia maya yang dilihat sebagai satu ruang selamat untuk mereka. Di dunia ini, mereka dikelilingi oleh individu yang memahami minat dan konflik belia yang dilalui mereka dan juga mereka saling memberi sokongan antara satu sama lain. Kebergantungan terhadap teknologi ini juga semakin hari mampu mengubah aktiviti-aktiviti harian mereka supaya lebih mesra internet 
atau media sosial. Peningkatan dalam kebergantungan terhadap media dalam talian membuktikan hubungan generasi $Z$ dengan fenomena gelombang Korea ini telah berada di fasa mediatisasi.

\section{KESIMPULAN}

Kesimpulannya, teknologi komunikasi media tanpa disedari mengubah cara manusia berkomunikasi dan juga budaya gaya hidup manusia. Perubahan ini mungkin berlaku tanpa disedari disebabkan oleh manusia melalui proses-proses perkembangan teknologi komunikasi media secara berperingkat dan sepanjang masa. Namun, disebabkan oleh perkembangan teknologi, aktiviti yang dilalui oleh generasi muda kini amat berbeza dengan generasi terdahulu. Proses pendigitalisasi membesarkan jurang antara generasi muda dengan generasi terdahulu. Apabila acara fizikal dimediasikan untuk mencapai para peminat, ini memperlihatkan satu perubahan yang jelas. Hanya disebabkan ia dilakukan dengan lebih tertutup, perbincangan juga hanya tertumpu dalam komuniti peminat semata-mata, menyebabkan ia tidak diketahui oleh pihak lain. Ini memperlihatkan perlunya lebih kajiankajian dilakukan di dalam talian untuk memahami dunia di sebalik peranti komunikasi media ini.

Penelitian sepanjang beberapa fasa tempoh perintah kawalan pergerakan ini membantu pengkaji memahami hubungan yang terbina di antara peminat dengan fenomena gelombang Korea. Walaupun dilanda pandemik global, teknologi komunikasi media mempunyai kuasa untuk membentuk cara manusia berkomunikasi dan masih boleh membentukkan suatu pergerakan kolektif. Apabila acara fizikal dimediasikan ianya memperlihatkan bagaimana fenomena gelombang Korea tidak kehilangan peminat, tetapi juga semakin bertambah di seluruh dunia. Ini adalah kerana mereka tidak lagi terikat dengan faktor-faktor fizikal yang mengekang mereka untuk lebih dekat dengan artis kegemaran mereka.

Di pihak artis Korea pula, mereka boleh dengan kemudahan yang ditawarkan dalam platform ini untuk mengurangkan harga tiket atau melakukan persembahan secara percuma. Mereka boleh melakukan acara fizikal mereka di ruang siber yang telah disediakan. Mereka tidak lagi perlu berjalan jauh, menaiki kenderaan atau menaiki kapal terbang, menyewa hotel, pihak keselamatan dan sebagainya. Namun, kesan negatif mungkin dihadapi oleh pihak lain seperti syarikat penerbangan, organisasi pengurus acara, industri perhotelan dan perkhidmatan lain berkaitan yang tidak lagi diperlukan. Bagi peminat, aktiviti peminat mungkin tidak sama tetapi ianya masih lagi boleh diteruskan. Ini menyebabkan peminat generasi Z kekal semakin bergantung pada media terutamanya dalam mengekalkan aktiviti peminat bersama artis kegemaran mereka.

Kebergantungan kepada media ini berkaitan dengan cara hubungan dibentuk melalui rangkaian media sosial, distrukturkan oleh perkembangan teknologi komunikasi media dan menghasilkan satu dunia kecil yang bersifat tersendiri. Bagi mereka yang tidak mendalami dunia kecil ini, mereka mungkin tidak berkongsi gelombang pemikiran yang sama serta merasakan tidak memahami hubungan yang wujud di antara peminat generasi $Z$ dengan fenomena ini. Walaupun diancam pandemik global, dunia kecil ini tidak terganggu malah lebih kukuh melalui proses mediasi dan mediatisasi.

Perlu ditekankan bahawa kajian ini memperlihatkan bagaimana teori mediatisasi dan budaya menerangkan tentang pengaruh media kepada sesuatu kumpulan dalam masyarakat. Kajian ini telah melihat kepada bagaimana kuasa media mempengaruhi cara manusia 
menggunakan media dan berkomunikasi yang berbeza dengan penggunaan generasi terdahulu. Teori mediatisasi dan budaya ini telah mengenal pasti rangka kerja untuk mengolah dan mendalami keadaan manusia masa ini terutamanya mereka yang menggunakan teknologi media dan komunikasi yang canggih. Perubahan dalam aktiviti masyarakat mungkin tidak disedari oleh manusia tetapi ianya telah memberikan implikasi dari segi percanggahan budaya dan norma kehidupan masyarakat. Budaya peminat gelombang Korea masih kekal sama di mana mereka meminati produk budaya daripada Korea Selatan. Namun kewujudan media sosial memperlihatkan pengaruh yang besar terhadap kehidupan harian mereka yang membezakan peminat generasi $Z$ dengan generasi sebelum ini. Komuniti peminat gelombang Korea bersifat lebih dinamik dan mampu menongkah arus evolusi. Lebih banyak kajian perlu dilaksanakan untuk melihat pengaruh kandungan media terhadap kehidupan mereka dan bagaimana komuniti dalam talian memberi kesan kepada kehidupan mereka di dunia dalam dunia realiti.

\section{PENGHARGAAN}

Artikel ini telah dibiayai oleh Geran Kecil Penyelidikan (GKP) FSSK, Universiti Kebangsaan Malaysia SK-2019-018.

\section{BIODATA}

Nurul Akqmie Binti Badrul Hisham ialah calon Doktor Falsafah di Pusat Kajian Media dan Komunikasi (MENTION), Fakulti Sains Sosial dan Kemanusiaan, UKM. Beliau juga merupakan salah seorang daripada IKMAS-Nippon Foundation Young Scholar Fellowship 2017/2018. Bidang pengkhususan beliau adalah Komunikasi Massa. E-mel: akqmie.othereye@gmail.com

Abdul Latiff Ahmad ialah pensyarah kanan di Pusat Kajian Media dan Komunikasi (MENTION), Fakulti Sains Sosial dan Kemanusiaan, UKM. Beliau juga adalah Pengarah di Pusat Hubungan Antarabangsa, UKM. Bidang pengkhususan beliau adalah Komunikasi Antara Budaya dan Masyarakat Digital. E-mel: alba@ukm.edu.my

Chang Peng Kee ialah pensyarah kanan di Pusat Kajian Media dan Komunikasi (MENTION) Fakulti Sains Sosial dan Kemanusiaan, UKM. Beliau juga adalah Pengarah Pusat Pembangunan Karier, UKM. Bidang pengkhususan adalah Perhubungan Awam dan Statistik. E-mel: chang@ukm.edu.my 


\section{RUJUKAN}

Addeo, F., Delli Paoli, A., Esposito, M., \& Ylenia Bolcato, M. (2019). Doing social research on online communities: The benefits of netnography. Athens Journal of Social Sciences, 7(1), 9-38. https://doi.org/10.30958/ajss.7-1-1

Conte, J. (2017). Virtual reality. In S. Burn (Ed.), American literature in transition 1990-2000 (Chap. 18, pp. 279-294). Cambridge University Press. https://doi.org/f4bs

Corner, J. (2018). 'Mediatization': Media theory's word of the decade. Media Theory. http://mediatheoryjournal.org/john-corner-mediatization/

Coronavirus disease (COVID-19) in Malaysia. (n.d.). Dicapai pada 8 Julai, 2020. https://www.who.int/malaysia/emergencies/

Costello, L., Mcdermott, M.-L., \& Wallace, R. (2017). Netnography: Range of practices, misperceptions, and missed opportunities. International Journal of Qualitative Methods, 16(1). https://doi.org/10.1177/1609406917700647

Couldry, N., \& Hepp, A. (2017). The mediated construction of reality. Polity.

Deuze, M. (2012). Media life. Polity.

Dolot, A. (2018). The characteristics of generation Z. E-Mentor, 74, 44-50. https://doi.org/10.15219/em74.1351

Doobo Shim. (2017, May 24). Riding the Korean wave in Southeast Asia. Fair Observer. https://www.fairobserver.com/region/asia pacific/korean-wave-k-pop-culturesoutheast-asia-news-45109/

Ferreira, C. (2015, May). Exploring virtual worlds: Conducting a netnographic research in second life. Estudos em Comunicação - Communication Studies, 19, 35-59. http://ec.ubi.pt/ec/19/index.html

Freberg, K., Graham, K., McGaughey, K., Freberg, L. A. (2010). Who are the social media influencers? A study of public perceptions of personality. Public Relations Review, 37(1), 9-12. https://doi.org/10.1016/i.pubrev.2010.11.001

Gaidhani, S., Arora, L., \& Sharma, B. K. (2019, January). Understanding the attitude of generation Z towards workplace. International Journal of Management, Technology and Engineering, 9(XI), 2804-2812. http://www.ijamtes.org/VOL-9-ISSUE-01-2019-2/

Hepp, A. (2009). Differentiation: Mediatization and cultural change. In K. Lundby (Ed.), Mediatization: Concept, changes, consequences (pp. 135-154). Peter Lang.

Hepp, A., Hjarvard, S., \& Lundby, K. (2010). Mediatization - Empirical perspectives: An introduction to a special issue. Communications, 35(3), 223-228. https://doi.org/10.1515/COMM.2010.012

Hjarvard, S. (2008). Mediatization of society. A theory of the media as agents of social and cultural change. Nordicom Review, 29(2), 105-134. https://doi.org/f2j8

Hodkinson, P. (2005). 'Insider research' in the study of youth cultures. Journal of Youth Studies, 2, 131-149.

Hutchings, S. (2020). Revolution from the margins: Commemorating 1917 and RT's scandalising of the established order. European Journal of Cultural Studies, 23(3), 315334. https://doi.org/10.1177/1367549419871342

Jang, G., \& Paik, W. K. (2012). Korean wave as tool for Korea's new cultural diplomacy. Advances in Applied Sociology, 2(3), 196-202. https://doi.org/f2j9

Jin, D. Y. (2012). Hallyu 2.0: The new Korean wave in the creative industry. International Institute Jurnal University of Michighan, 2(1). http://hdl.handle.net/2027/ 
Jung, S., \& Shim, D. (2014). Social distribution: K-pop fan practices in Indonesia and the "Gangnam Style" phenomenon. International Journal of Cultural Studies, 17(5), 485501. https://doi.org/10.1177/1367877913505173

Kaplan, E. B. (2020). The millennial/gen z leftists are emerging: Are sociologists ready for them? Sociological Perspectives, 63(3), 408-427. https://doi.org/f4bt

Khadijah Mohamad Tuah, \& Ummu Syafiqah Mazlan. (2020). Twitter as safe space for selfdisclosure among malaysian LGBTQ youths. Jurnal Komunikasi: Malaysian Journal of Communication, 36(1), 436-448. https://doi.org/10.17576/JKMJC-2020-3601-25

Kim, B. R. (2015). Past, present and future of hallyu (Korean Wave). American International Journal of Contemporary Research, 5(5). http://www.aijcrnet.com/947

Kim, M. (2011). The role of the government in cultural industry: Some observations from Korea's experience. Keio Communication Review, 33.

http://www.mediacom.keio.ac.jp/blog/

Korean Culture and Information Service. (2011). The Korean wave: A new pop culture phenomenon.

Kozinets, R. V. (2010). Netnography: Doing ethnographic research online. International Journal of Advertising, 29(2), 328-330. https://doi.org/10.2501/S026504871020118X

Kozinets, R. V. (2002). The field behind the screen: Using netnography for marketing research in online communities. Journal of Marketing Research, 39, 61-72. https://doi.org/10.1509/jmkr.39.1.61.18935

Kozinets, R. V. (2015). Netnography. In P. H. Ang \& R. Mansell (Eds.), The international encyclopedia of digital communication and society. John Wiley \& Sons. https://doi.org/10.1002/9781118767771.wbiedcs067

Krotz, F. (2007). The meta-process of 'mediatization' as a conceptual frame. Global Media and Communication, 3, 256-260.

Lim, J. B. Y. (2013). Engaging participantion: Youth culture and the Korean wave in Malaysia. In M. J. Ainslie \& J. B. Y. Lim (Eds.), The Korean wave in Southeast Asia: Consumption and cultural production (pp. 155-174). SIRD Malaysia.

Lindlof, T. R., \& Taylor, B. C. (2011). Qualitative communication research methods (3rd ed.). Sage Publications.

Nazra Aliff Nazri, \& Abdul Latiff Ahmad (2020). Drama adaptasi Korea: Suatu analisis terhadap pemaparan Islam dalam drama My Coffee Prince. E-Bangi, 17(1), 24-36. https://ejournal.ukm.my/ebangi/article/view/37495

Nor Hasimah Jalaluddin, \& Zaharani Ahmad. (2011). Hallyu di Malaysia: Kajian sosio-budaya. Jurnal Komunikasi: Malaysian Journal of Communication, 27(2). https://ejournal.ukm.my/mjc/article/view/15089

Norbaiduri Ruslan, \& Siti Sakinah Abdul Latif. (2016). Malay women readings of Korean drama. Journal of Education and Social Sciences, 4, 343-365. http://irep.iium.edu.my/55298/

Nurul Akqmie Badrul Hisham, Abdul Latiff Ahmad, \& Chang Peng Kee. (2019). A reflection of ethnographic exploration on Korean wave enthusiasts in Malaysia. Jurnal Komunikasi: Malaysian Journal of Communication, 35(4), 286-304. https://doi.org/f2ki

Pandian, A., Baboo, S. B., \& Yi, L. J. (2020). Digital storytelling: Engaging young people to communicate for digital media literacy. Jurnal Komunikasi: Malaysian Journal of Communication, 36(1), 187-204. https://doi.org/10.17576/JKMJC-2020-3601-11 
Prayoga, K. (2020). How Jokowi communicates with the public during Covid-19 crisis: An analysis of tweets on Twitter. Jurnal Komunikasi: Malaysian Journal of Communication, 36(2), 434-456. https://doi.org/10.17576/JKMJC-2020-3602-26

Ravina, \& Mark. (2009). Introduction: Conceptualizing the Korean Wave. Southeast Review of Asian Studies, 31, 3-9. http://www.asia-studies.com/2seras09.html

Schulz, W. (2004). Reconstructing mediatization as an analytical concept. European Journal of Communication, 19(1), 87-101. https://doi.org/10.1177/0267323104040696

Seo, M. S., Jung, T. S., Jung, Y. M., \& Lee, H. W. (2013). Six strategies for sustainable growth of new Korean wave [issue report, pp. 9-13]. Samsung Economic Research Institute. http://www.seriworld.org/01/

Turner, G. (2016). Re-inventing the media. Routledge.

Wiktorowicz, Q. (2004). Conceptualizing Islamic activism. ISIM Newsletter 14, (June 2004), 34-35.

Wimmer, R. D., \& Dominick, J. R. (2014). Mass media research: An introduction (10th ed.). Wadsworth Cengage Learning.

Wojtkowski, Ł. (2017). The present tense of mediatization studies. Mediatization Studies, 1 , 9-22. http://dx.doi.org/10.17951/ms.2017.1.9

Yoon, S. Y. (2020, June 14). [Post-Covid-19 New Normal] K-pop finds solace online, but how long can it really last? Korea JoongAng Daily. https://koreajoongangdaily.joins.com/2020/06/14/culture/features/

Zainudin Awang. (2010). Research methodology for business and social science. UPENA. 